\title{
Proceeding
}

8th INSHS International Christmas Sport Scientific Conference, 5-7 December 2013. International Network of Sport and Health

Science. Szombathely, Hungary

\section{Anthropometric characteristics in Czech elite female gymnasts}

\author{
PETR HEDBÁVNÝ , JAN CACEK, LENKA SVOBODOVÁ \\ Faculty of Sport Studies, Masaryk University Brno, Czech Republic
}

\begin{abstract}
Hedbávný, P., Cacek, J. \& Svobodová, L. (2014). Anthropometric characteristics in Czech elite female gymnasts. J. Hum. Sport Exerc., 9(Proc1), pp.S481-S489. The aim of this paper is a description of selected parameters of body composition of elite sport gymnasts from the Czech Republic (30th place at 2010 World Championship). Eight Czech representatives (aged $18.4+3.39$ ) participated in this cross-sectional study realized in 2013. Data were measured according to standard testing protocols. Body height and arm spread via anthropometer (cm), body composition and body weight using 6-frequncy bio impedance (InBody 720), circumference characteristics using band meter. Body height of the researched group was $161.0 \mathrm{~cm}$ $(+5.34)$, compared to average body height of American Olympic team (2nd in World ranking) was only $153 \mathrm{~cm}$ in $2008(+7)$ (Sands et al. 2012). Body weight of Czech gymnasts was $55.7 \mathrm{~kg}(+5.46)$, American women gymnasts according to Sandse et al. weighed only $47.5 \mathrm{~kg}(+5.7)$. BMl (kg.m-2) was measured 21.35 (+ 1.66) which is a higher value than according to Grasgruber et al (2008) an average value of this parameter in participants of 2003 World Championship finals (18.77 Europeans, 16.73 Asians). Average amount of subcutaneous fat $13.33 \%(+2.81)$ was, on the contrary, lower than stated by Georgopoulos et al. in a study of 113 participants of European and World championships in last 15 years $(16.4 \% ;+4.99)$. Hip-waist ratio was $0.85(+0.03)$. Arm spread, particularly important in gymnastics due to effectiveness of leverage mechanisms, was measured $164.9 \mathrm{~cm}(+6.85)$, showing relatively long leverages, or aboveaverage shoulder width considering average height of the group $161 \mathrm{~cm}$. Long leverages are beneficial for floor exercise and vault. Overall, compared to World competition, Czech gymnasts show above-average height as well as BMI value. Considering relatively low amount of subcutaneous fat we speculate that compared to elite world competition, Czech gymnasts will show higher relative values of skeletal muscles which may disadvantage them in some aspects of performance. Key words: SOMATIC CHARACTERISTICS, SPORT GYMNASTICS, THE CZECH REPUBLIC.
\end{abstract}

Corresponding author. Faculty of Sport Studies, Masaryk University Brno, Czech. Republic.

E-mail: gaydin@anadolu.edu.tr

8th INSHS International Christmas Sport Scientific Conference, 5-7 December 2013. International Network of Sport and Health Science. Szombathely, Hungary.

JOURNAL OF HUMAN SPORT \& EXERCISE ISSN 1988-5202

(c) Faculty of Education. University of Alicante

doi:10.14198/jhse.2014.9.Proc1.36

VOLUME 9 | Proc1 | 2014 | S481 


\section{INTRODUCTION}

Sport gymnastics have been historically the most successful sport in Czechoslovak, and then in the Czech Olympic history, therefore we try to discover the reasons of contemporary level of our female representatives who ranked 30th at the last world championship. We hope that this study will contribute to discovering the reason of their non-success and will help to find the ways out of the crisis.

After WW2 at the 1948 Olympic Games in London the female artistic gymnasts' team from Czechoslovakia won gold medals and the team remained at the high-ranking positions until 1968 when the Czechoslovak team of female artistic gymnasts triumphed with 6 Olympic medals (Martínková, 1981). It was in 1988 when the female team managed to qualify for the Olympic Games and ranked 7th. Since 1988 Olympic Games only individual female artistic gymnasts have participated in Olympic Games (Dobrovodský, 1989). At 2010 World Championship in Rotterdam the Czech team ranked 30th, which is historically the worst achievement. The current condition is not a result of a single cause, however, we think that this study may help to solve the crisis at which the Czech artistic gymnastics lies.

Every type of sport performed on a professional level places demands on somatotype characteristics and its parameters (Carter \& Heath, 1990). In past 50 years artistic gymnastics moved considerably forward considering the technique and exercise difficulty. This trend is reflected in anthropometric characteristics of professional gymnasts, such as height, body weight, BMI, arm spread, WHE, \% of body fat and other.

As mentioned above, the Czech artistic gymnastics ruled the world until 1968, therefore we want to start the comparison right in this period of the biggest fame of the Czech artistic gymnastics (Hirata, 1966). At 1964 Olympic Games in Tokyo the average age of participants was 22.7 years, the average weight $52 \mathrm{~kg}$, the average height $157 \mathrm{~cm}$ from 102 gymnasts considered. The BMl can thus be calculated - 21.1. At the following 1968 Olympic Games in Mexico only the average age of the sportswomen changed considerably, De Garay et al. (1974) state the average values - age 17.8 years, height 156.9, weight 49.8 , however only 21 female sports gymnasts were measured. The responding BMI is 20.13. At 1972 Olympic Games in Munich where 133 participants were measured Hirata (1979a, 1979b) states the age 19.0 years, height 159, weight 49.5 with corresponding BMII 19.38. Lopez et al. (1979) state the research results from 1976 Olympic Games in Montreal where 99 female participants had following average results: age 18.2, height 158.6, weight 47.4, BMI 18.68. Another available sample was 161 female participants of 1983 World Championship in Budapest (Gajdos, 1984) where the average age of the participants was under $17-16.8$ years, height 154.4, weight 44.0, BMl 18.55. The last bigger complex analysis of anthropometric data was conducted at 1987 World Championship in Rotterdam in 1987 (Cleassens et al., 1991) where 201 probands was of average age 16.5 , height 154.3 , weight 45.6 and with corresponding BMI 18.97.

As can be seen from the above mentioned values, the anthropometric characteristics of the female artistic gymnasts participating in elite competitions stabilized after 1976 when BMI got under 19. This level can be considered as optimal for achieving average results in this sports field. As dominant is here body height which advantages the female artistic gymnasts in many aspects, mainly when exercising on uneven bars and balancing beam (Cleassens et al., 1999). The maximum width of bars is given by rules and cannot be regulated according to competitor's needs, therefore a taller gymnast is to some extend disadvantaged. In balancing beam which is $10 \mathrm{~cm}$ wide is a taller competitor disadvantaged as well. Taller gymnasts may benefit in vault, however the contemporary equipment constructions and vault technique Yurchenko enables also taller gymnasts to perform a vault with a difficulty corresponding to multicontest competition, but they cannot perform the vault in such extend as the gymnasts of lower height. We are interested in 
where our elite female artistic gymnasts can be classed according to anthropometric prerequisites. From this reason this study focuses on identification and description of anthropometric parameters of our elite female artistic gymnasts and their comparison with the parameters of the best female world sport gymnasts in the world.

\section{Aim}

The aim of this work is to describe and compare selected somatotopic parameters of elite Czech and world's female gymnasts.

\section{MATERIAL AND METHODS}

\section{Research sample}

Cross section study of selected somatotopic characteristics was conducted in 2013. Data of 8 elite Czech female gymnasts (representatives in gymnastic multicontest) were measured during an international competition "Jan Gajdoš Memorial" in Brno. The average age at the time of data acquisition was 18.4 \pm 3.39. Parents of girls aged less than 18 signed an inform consent with the measurement. All sportswomen participated in the research consentingly and with parents' and trainers' consent.

\section{Measurements}

A study protocol included laboratory and clinical non-invasive measurement of body composition, body height, weight, and height in sitting position. Body height was measured using standard measurement procedure and with a standard scale. Laboratory measurement was conducted with the aim of finding out the selected aspects of body composition and body weight.

The measurement was conducted on a device InBody 720 (Biospace, Korea), and the identified parameters were: \% of body fat, waist to hip ratio (WHR), body weight, BMI. Before the measurements the tested persons followed the instructions of the device producer regarding the body hydration.

The results of the selected parameters (BMI, body height and weight) of the Czech gymnasts were compared with data of finalists in gymnastic multicontest (8 women) and finalists on individual gymnastic equipment ( 8 women in each discipline) form the 2008 Olympic Games in Beijing. The number of compared data in some equipment was influenced by missing data of the competitors. Instead of data from 8 finalists some data were statistically analysed with only 7 women. Authors are aware of the fact that the stated data from the Olympic Games were not obtained using the same techniques and devices as the data of Czech gymnasts.

Statistic processing

Two group t-test for independent variable was used to compare data between two different groups. Significance level was set to $5 \%$. All statistics were realized using a programme Statistica version 12 .

\section{RESULTS}

The average values of data for all tested parameters in all Czech female sport gymnasts are stated in Table 1. It results from the table that average body height of Czech gymnasts is $161 \mathrm{~cm}$ (SD 5.34), average body weight is $55.7 \mathrm{~kg}(\mathrm{SD} \mathrm{5,46)}$ and average BMl was measured 21.35 (SD 1.66). 
When comparing somatotopic characteristics of elite Czech gymnasts with finalist of Olympic Games in Beijing (Table 2) we found out that Czech gymnasts show significant differences compared to elite Olympic gymnasts in all observed disciplines, in both all gymnastic disciplines and gymnastic multicontest.

Table 1. Basic statistical characteristics of Czech female sport gymnasts

\begin{tabular}{|c|c|c|c|c|c|}
\hline \multirow[b]{2}{*}{ Variable } & \multicolumn{5}{|c|}{ Descriptive Statistics } \\
\hline & Valid N & Mean & Minimum & Maximum & Std.Dev. \\
\hline BMI W4 & 8 & 18,4075 & 15,5600 & 21,9300 & 1,988494 \\
\hline Body Height W4 (cm) & 8 & 148,5000 & 138,0000 & 160,0000 & 7,289915 \\
\hline Body Weight W4 (kg) & 8 & 40,7500 & 32,0000 & 52,0000 & 6,519202 \\
\hline BMI WV & 8 & 19,5450 & 18,3100 & 22,0600 & 1,245346 \\
\hline Body Height WV (cm) & 8 & 155,1250 & 151,0000 & 165,0000 & 4,580627 \\
\hline Body WeightWV (kg) & 8 & 47,1250 & 43,0000 & 55,0000 & 4,823677 \\
\hline BMI WB & 7 & 18,6371 & 15,5600 & 20,5700 & 1,742582 \\
\hline Body Height WB (cm) & 8 & 152,8750 & 138,0000 & 161,0000 & 7,567553 \\
\hline Body Weight WB (kg) & 7 & 43,8571 & 35,0000 & 53,0000 & 7,174691 \\
\hline BMI WBB & 7 & 17,9829 & 17,1000 & 19,5000 & 0,927590 \\
\hline Body Height WBB (cm) & 8 & 149,8750 & 141,0000 & 160,0000 & 6,749339 \\
\hline Body Weight WBB (kg) & 7 & 39,8571 & 34,0000 & 45,0000 & 4,180453 \\
\hline BMI WF & 8 & 19,0913 & 16,3300 & 21,9300 & 1,852824 \\
\hline Body Height WF (cm) & 8 & 149,2500 & 140,0000 & 160,0000 & 6,386369 \\
\hline Body Weight WF (kg) & 8 & 42,6250 & 32,0000 & 52,0000 & 5,629958 \\
\hline \%BF CZ & 8 & 13,3250 & 10,1000 & 16,9000 & 2,809550 \\
\hline WHR CZ & 8 & 0,8475 & 0,8000 & 0,8900 & 0,029155 \\
\hline $\mathrm{BMI} \mathrm{CZ}$ & 8 & 21,3500 & 19,1000 & 23,5000 & 1,657020 \\
\hline Body Weight CZ (kg) & 8 & 55,7000 & 48,4000 & 63,7000 & 5,455796 \\
\hline Body Height CZ $(\mathrm{cm})$ & 8 & 161,0250 & 152,2000 & 170,0000 & 5,338472 \\
\hline
\end{tabular}

Table 2. Anthropometric parameters of finalist of 2008 Olympic Games in Beijing

\begin{tabular}{|c|c|c|c|c|c|c|c|c|c|c|c|c|c|c|}
\hline BMI & $\mathrm{TH}$ & TV & $\mathrm{BMI}$ & $\mathrm{TH}$ & TV & $\mathrm{BMI}$ & $\mathrm{TH}$ & TV & $\mathrm{BMI}$ & $\mathrm{TH}$ & TV & BMI & $\mathrm{TH}$ & TV \\
\hline 17,58 & 160 & 45 & 18,31 & 155 & 44 & & 152 & $\mathrm{~N}$ & 19,5 & 145 & 41 & 21,93 & 154 & 52 \\
\hline 19,5 & 145 & 41 & 18,8 & 153 & 44 & 17,58 & 160 & 45 & 17,58 & 160 & 45 & 19,5 & 145 & 41 \\
\hline 15,56 & 150 & 35 & 18,61 & 152 & 43 & 15,56 & 150 & 35 & 18,61 & 152 & 43 & 17,58 & 160 & 45 \\
\hline 18,38 & 138 & 35 & 22,06 & 155 & 53 & 20,57 & 159 & 52 & 18,61 & 152 & 43 & 16,33 & 140 & 32 \\
\hline 19,37 & 149 & 43 & 20,2 & 165 & 55 & 18,55 & 154 & 44 & 17,36 & 146 & 37 & 18,77 & 146 & 40 \\
\hline 16,33 & 140 & 32 & 20,03 & 158 & 50 & 18,38 & 138 & 35 & 17,12 & 145 & 36 & 18,61 & 152 & 43 \\
\hline 18,61 & 152 & 43 & 19,74 & 151 & 45 & 19,37 & 149 & 43 & 17,1 & 158 & 34 & 18,61 & 152 & 43 \\
\hline 21,93 & 154 & 52 & 18,61 & 152 & 43 & 20,45 & 161 & 53 & & 141 & & 21,4 & 145 & 45 \\
\hline 18,41 & 149 & 40,8 & 19,55 & 155 & 47 & 18,64 & 153 & 44 & 17,98 & 150 & 40 & 19,09 & 149,3 & 42,6 \\
\hline & \multicolumn{2}{|c|}{$\begin{array}{l}\text { All- } \\
\text { around }\end{array}$} & \multicolumn{3}{|c|}{ vault } & & \multicolumn{2}{|c|}{$\begin{array}{l}\text { Uneven } \\
\text { bars }\end{array}$} & & \multicolumn{2}{|c|}{$\begin{array}{l}\text { Balance } \\
\text { beam }\end{array}$} & \multicolumn{3}{|c|}{ Floor } \\
\hline
\end{tabular}


In BMI values (Fig. 1) the differences on $p<0.05$ were identified between Czech gymnasts $(n=8)$ and $O G$ finalists $(n=8)$ in multicontest $p=0.0062$ (BMI 21.35 vs 18.40), with OG finalists in vault $(n=8)$, where the value $p=0.027$ (BMl 21.35 vs19.54), with OG finalist in uneven bars $(n=7) p=0.0086$ (BMI 21.35 vs 18.64), with finalists on balancing beam $(n=7) p=0.0003$ (BMI 21.35 vs 17.98) and finalist on floor $(n=8)$ where $p=0.0222$ (BMI 21.35 vs 19.09).

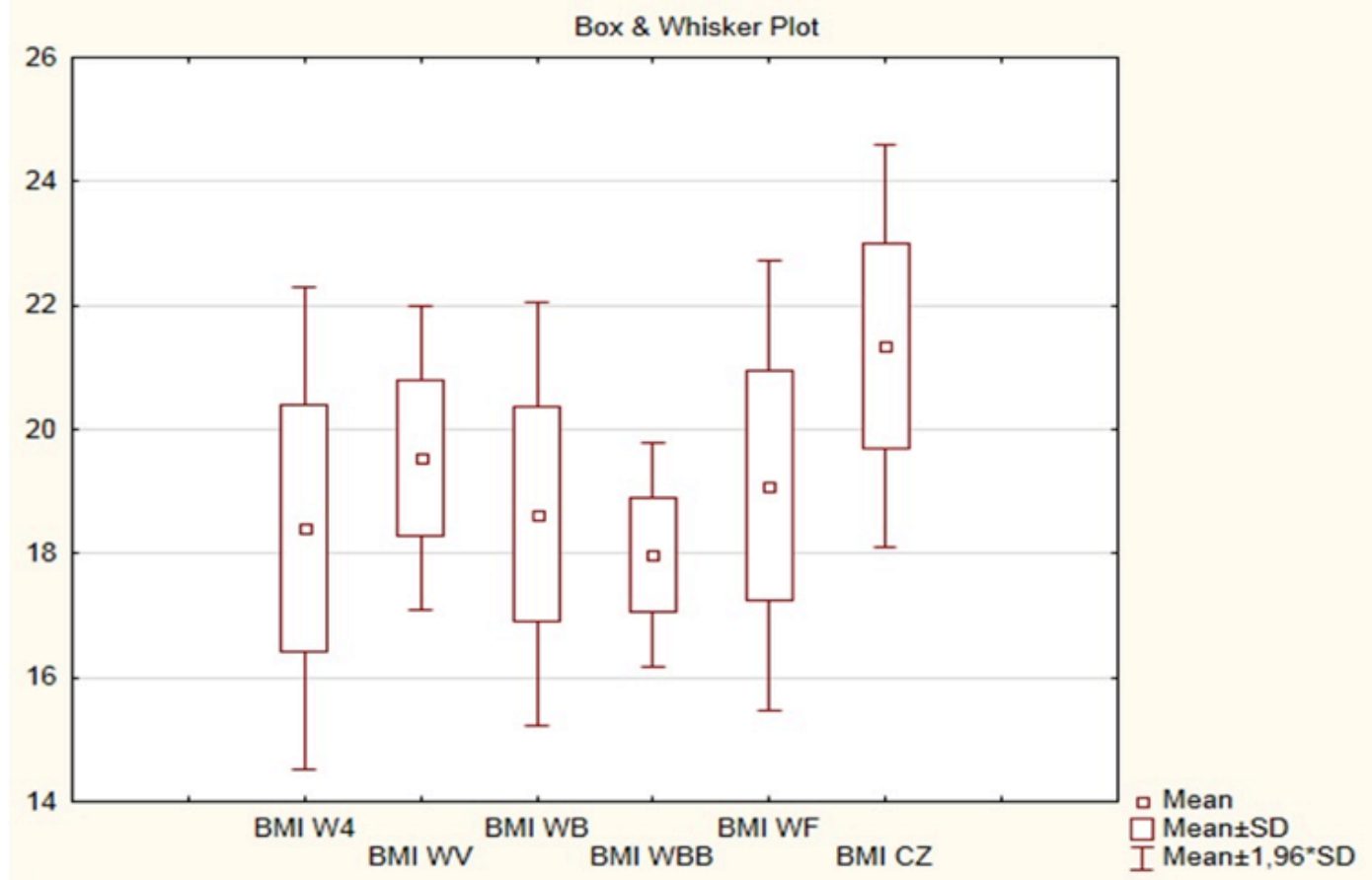

Figure. 1. Box BMI of gymnasts, finalists (according to disciplines) 2008 Olympic Games in Beijing and elite Czech gymnasts; $W 4=$ finalists of $O G$ in multicontests; $W V=$ finalists of $O G$ in vault; $W B=$ finalists of $O G$ in uneven bars; $W B B=$ finalists of $O G$ in balancing beam; $W F=$ finalists of $O G$ in floor exercise; $C Z$ = elite Czech gymnasts.

Similar results and statistically significant differences $p<0.05$ were observed also in parameter body height $(\mathrm{BH})$ between the best Olympic gymnasts and elite Czech gymnasts (Fig. 2). Czech gymnasts showed higher values of $\mathrm{BH}(161$ vs 148.5$)$ than OG finalists $(n=8)$ in multicontest $(p=0.0015)$, in vault $(n=8)$, where $P=0.0325(B H 161$ vs 155.1), in uneven bars $(n=8)$, where $p=0.0260(B H 161$ vs 152.9), in balancing beam $(n=8)$, where $p=0.0025(B H 161$ vs 149.9), in floor exercise $(n=8)$, where $p=0.0013(B H$ 161 vs 149.2).

Comparison of values of body weight (BW) shows a significant higher weight of Czech gymnasts compared to elite world's gymnasts. Czech gymnasts had average weight $55.7 \mathrm{~kg}$ compared to weight of $40.8 \mathrm{~kg}$ $(p=0.0002)$ of elite world's female gymnasts doing multicontest $(n=8)$. Similarly, elite Olympic gymnasts in vault $(n=8)$ had lower average value of body weight $47.1 \mathrm{~kg}(P=0.0050)$ than elite Czech gymnasts $(55.7$ $\mathrm{kg})$. An average value of BW of world's uneven bars gymnasts $(n=7)$ was $43.86 \mathrm{~kg}(p=0.0031)$ and elite balancing beam gymnasts $(n=8)$ was $39.86(p=0.0003)$. An average value of BW of gymnasts on floor $(42.6$ vs 55.7) was again lower in Olympic gymnasts $(n=8)$, than in Czech elite gymnasts $(p=0.0003)$. The lowest BW values had OG finalists doing balancing beam and multicontest (Fig. 3). Other observed parameters were obesity indicators: amount of subcutaneous fat and waist-hip ratio (WHR). Elite Czech gymnasts showed values $13.3 \%$ (SD 2.81) of fat and WHR = 0.85 (SD 0.03). 


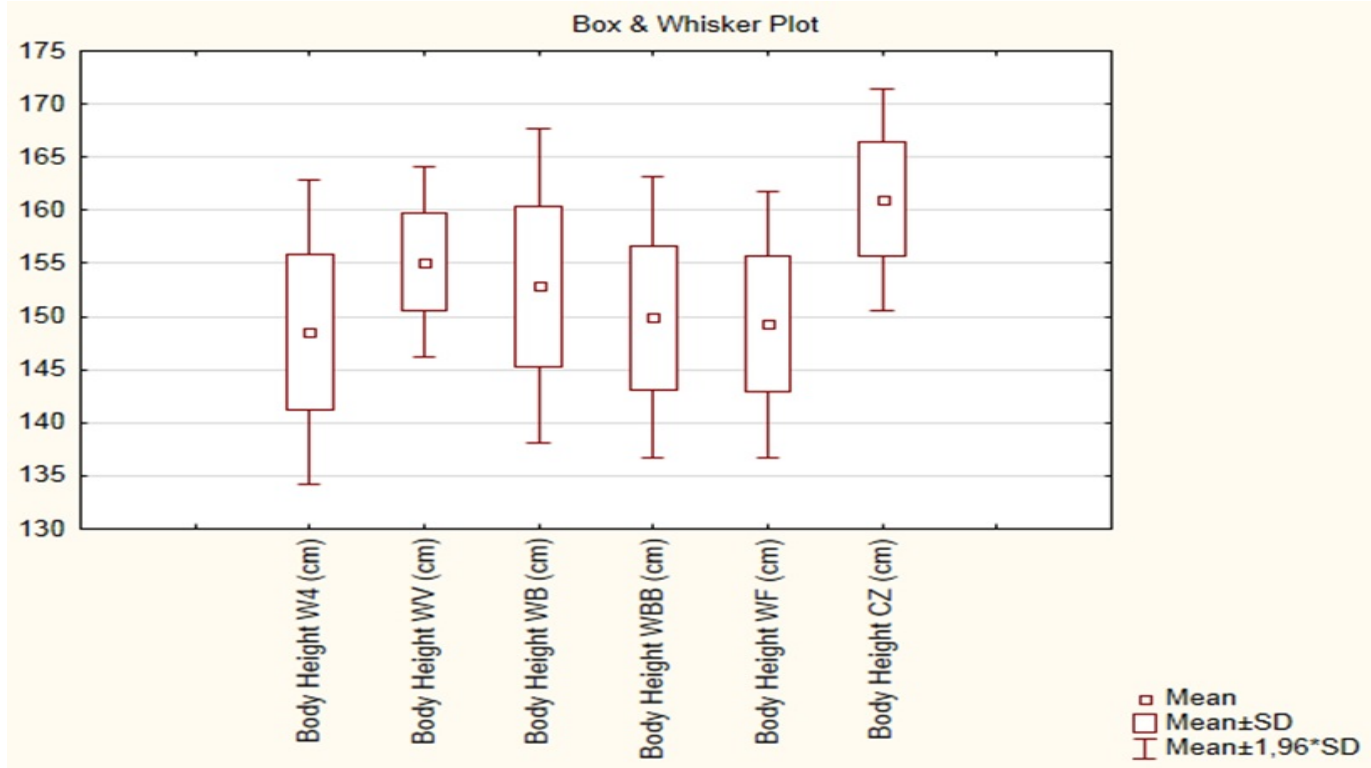

Figure. 2. Box plot of body height of female gymnasts, finalists (according to disciplines) of 2008 OG in Beijing and elite Czech gymnasts; $W 4$ = finalists of $O G$ in multicontest; $W V=$ finalists of $O G$ in vault; $W B=$ finalists of $O G$ in uneven bars; $W B B=$ finalists of $O G$ in balancing beam; $W F=$ finalists of $O G$ in floor exercise; $C Z$ = elite Czech gymnasts.

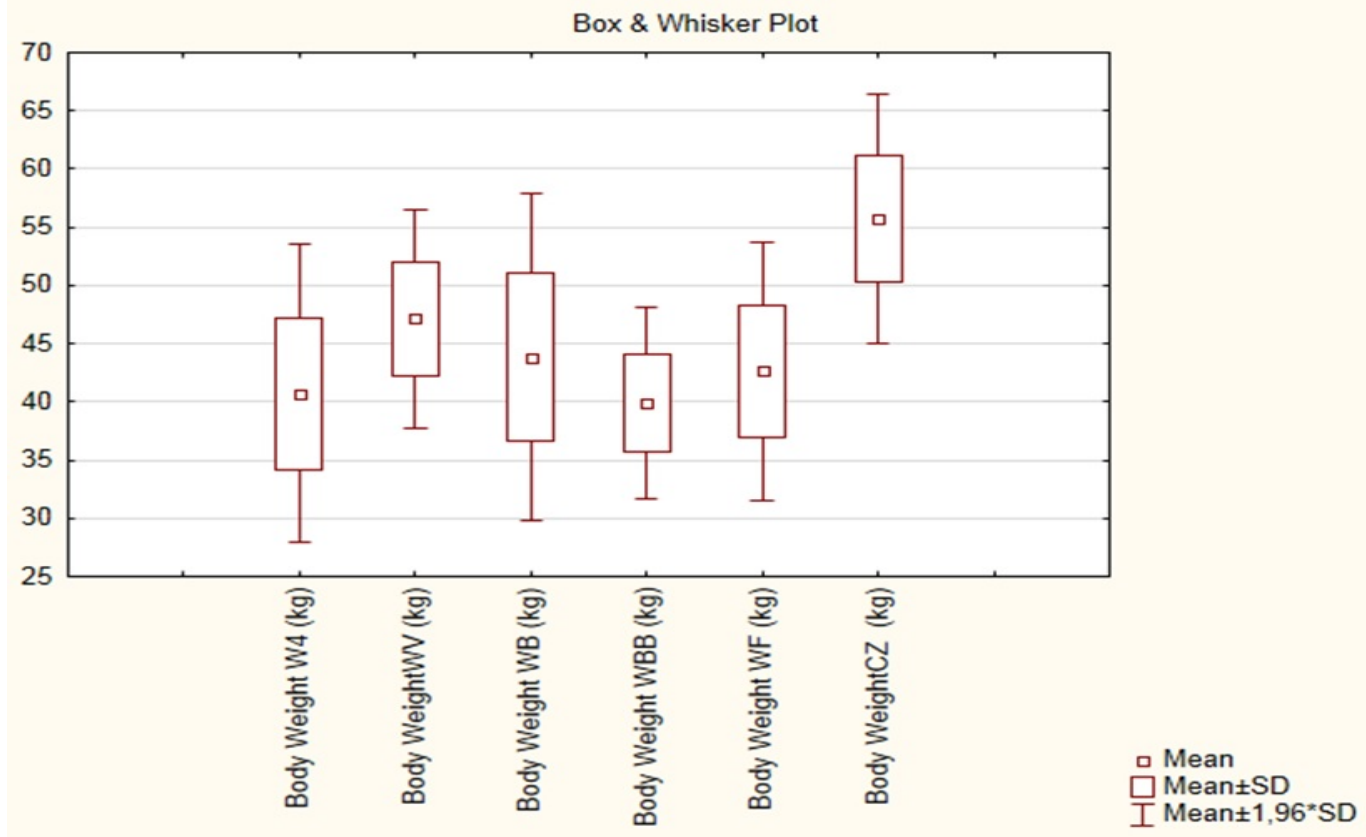

Figure. 3. Box plot of body height of female gymnasts, finalists (according to disciplines) of $2008 \mathrm{OG}$ in Beijing and elite Czech gymnasts; $W 4=$ finalists of $O G$ in multicontest; $W V=$ finalists of OG in vault; $W B=$ finalists of OG in uneven bars; $W B B=$ finalists of $O G$ in balancing beam; WF = finalists of OG in floor exercise; $C Z$ = elite Czech gymnasts. 


\section{DISCUSSION}

When comparing the data with values measured at world competitions in the past (Table 3) we may point out that the body composition of Czech female gymnasts correspond to parameters of gymnasts competing in 1964 Olympic Games in Tokyo.

Table 3. Basic anthropometric parameters of gymnasts at world's competitions and contemporary Czech elite female gymnasts

\begin{tabular}{|c|c|c|c|c|c|}
\hline tournament & $\mathrm{n}$ & Age(year) & Height $(\mathrm{cm})$ & Weight(kg) & BMI \\
\hline $\begin{array}{l}\text { OG Tokyo1964 } \\
\text { ( Hirata, 1966) }\end{array}$ & 102 & 22,7 & 157 & 52 & 21,1 \\
\hline $\begin{array}{l}\text { OG Mexico } 1968 \\
\text { ( Garay et.al., 1974) }\end{array}$ & 21 & 17.8 & 156,9 & 49,8 & 20,13 \\
\hline $\begin{array}{l}\text { OG Munich } 1972 \\
\text { (Hirata } 1979 \mathrm{a}, \mathrm{b} \text { ) }\end{array}$ & 133 & 19 & 159 & 49,5 & 19,38 \\
\hline $\begin{array}{l}\text { OG Montreal } 1976 \\
\text { (in Lopez et al., 1979) }\end{array}$ & 99 & 18,2 & 158,6 & 47,4 & 18,68 \\
\hline $\begin{array}{l}\text { WC Budapest } 1983 \\
\text { (Gajdos 1984) }\end{array}$ & 161 & 16,8 & 154,4 & 44 & 18,55 \\
\hline $\begin{array}{l}\text { WC Rotterdam } 1987 \\
\text { (Claessens 1991) }\end{array}$ & 201 & 16,5 & 154,3 & 45,6 & 18,97 \\
\hline OG Beijing 2008 & 98 & & 154,1 & 45.7 & 18,97 \\
\hline Czech elite gymnasts & 8 & 18,4 & 161,3 & 55,3 & 21,22 \\
\hline
\end{tabular}

Comparison of elite Czech and world female gymnasts show some interesting differences which may be important from the point of view of performance limitation of elite Czech gymnasts. Globally, Czech gymnasts show, compared to world competition, above-average height, weight and BMI values. Body height of the selected group was $161.0 \mathrm{~cm}( \pm 5.34)$, on the contrary, average height of American Olympic team (2nd in World ranking) was only $153 \mathrm{~cm}$ in 2008 ( \pm 7 ) (Sands et al., 2012). The body weight of Czech gymnasts was $55.3 \mathrm{~kg}( \pm 5.46)$, American gymnasts according to Sands et al. weighed only $47.5 \mathrm{~kg}( \pm$ 5.7). BMl (kg.m-2) was measured 21.35 ( \pm 1.66), which is a higher value than average value of the parameter of finalists in 2003 World Championship - 18.77 Europeans, 16.73 Asians (Grasgruber \& Cacek, 2008). Average amount of subcutaneous fat $13.33 \%( \pm 2.81)$ was, on the contrary, lower than stated by Georgopoulos et al. (2012) in the study of 113 participants of European and World Championships in the past 15 years $(16.4 \% ; \pm 4.99)$. Regarding the low amount of subcutaneous fat we speculate that compared to elite world competition Czech female gymnasts will have higher relative values of skeletal muscles which may disadvantage them in some aspects.

Although multicontest is still a dominant gymnastic discipline, in our opinion, only gymnastic powers, such as the USA, China, Russia, and Romania may afford to have a multicontest female gymnasts with medal ambitions on a world competition. Smaller countries with far smaller base. Such as the Czech Republic, must focus on disciplines corresponding with their somatotopic predispositions for a given discipline. 
Talent selection is also important as somatotype plays an important role here (Malina et al., 1997). It is very difficult to make this process more effective in conditions in the Czech Republic, as sports gymnastics, despite being historically the most successful Olympic sport, is not as popular as in the past. Only bigger centres can afford to select talented individuals and dedicate time for their preparation from an early childhood. However, also these centres face lack of qualified junior trainers. The biggest problem is wasted potential in smaller towns with limited conditions for quality training. This results in a fact that a talented individual with corresponding somatotopic parameters ends his carrier too early despite having more potential than competitors who are led by qualified trainers, but their somatotopic predispositions are so limiting that they cannot compare themselves with the best world gymnasts.

\section{CONCLUSIONS}

Due to a decreasing level of sports gymnastics in the Czech Republic in this work we focused on an analysis of one of the possible reasons of this state, and it was anthropometric characteristics of elite female gymnasts. We evaluated 20 values of 8 representatives of the Czech Republic. We compared the basic parameters, body height, weight and BMI, with available data. From the results it is obvious that none of the three characteristics of our gymnasts approaches the average values of gymnasts competing in world competitions, not even the finalist of these competitions. The reasons may be not only in dysfunctional talent selection, but also in wrong condition preparation during the training process. Excessive muscle gain noticed in our female gymnasts may result from wrongly chosen methods of development of strength abilities. We came to conclusion that Czech elite female gymnasts are, regarding their body composition, capable of being successful in vault.

\section{REFERENCES}

1. Carter, J.E.L. \& Heath, B.H. (1990). Soomatotyping: development and applications. Cambridge: Cambridge University Press.

2. Claessens, A.L., Veer, F.M., Stijnen, V., Lefevre, J., Maes, H., Steens, G. \& Beunen, G. (1991). Anthropometric Characteristic of outstanding male and female gymnasts. J Sport Sci, 9 (1), pp.5374.

3. Claessens, A.L., Lefevre, J., Beunen, G. \& Malina, M. (1999). The contribution of anthropometric characteristics to performance scores in elite famale gymnasts. J Sport Med Phys Fit, 39, pp.35560.

4. De Garay, A.L., Levine, L. \& Carter J.E.L. (1974). Genetik and Antropological Studies of Olympic Athletes. New York: Academic Press.

5. Dobrovodský, V.(1989). Hry XXIV. olympiády: Soul 1988. Praha, Czech: Olympia.

6. Gajdos, A. (1984). Alter, Korpergrose and gewicht bei Kunstturnern und Kunstturnerinnen der W. M. 1983 in Budapest. Leistugssport, 14, pp.17-18.

7. Georgopoulos, N.A., Theodoropoulou, A., Roupas, N.D., Rottstein, L., Tsekouras, A., Mylonas, P. \& Markou, K.B. (2012). Growth velocity and final height in elite female rhythmic and artistic gymnasts. Hormones, 11(1), pp.61-69.

8. Grasgruber, P. \& Cacek, J. (2008). Sportovni geny: antropometrie a fyziologie sportu, sport a rasa, doping. Brno, Czech: Computer press.

9. Hirata, K. (1966). Physique and age of Tokyo Olympicchampions. J Sport Med Phys Fit, 6, pp.20722.

10. Hirata, K. (1979a). Age and Physique of Montreal Olympic World Champions. Journal for Research in Sport, Physical Educationand recreation, 2, pp.111-21. 
11. Hirata, K. (1979b). Selection of Olympic Champions. Vol.II. Tokyo: Chukyo University.

12. Lopez, A., Rojas, J. \& Garcie, E. (1979). Somatotype et composition du corps chez lesgymnastes de haut niveau. Cinesiologie, 72, pp.5-18.

13. Malina, R.M. Et al. (1997). Growth and maturation elite female gymnast: is training a factor? In: Johnston, F.E. \& Zemel, B. editors. Human growth and development. Philadelphia USA: Proceedings of the 8th Int Congr Auxology.

14. Martínková, A. (1981). Malá encyklopedie olympijských her. Praha, Czech: Olympia.

15. Sands, W.A., Slater, C., McNeal, J.R., Murray, S.R., \& Stone, M.H. (2012). Historical trends in the size of US olympic female artistic gymnasts. International Journal of Sports Physiology and Performance, 7(4), pp.350-356. 